\title{
Recurrent Acute Myeloid Leukemia with Myelodysplasia-Related Changes
}

National Cancer Institute

\section{Source}

National Cancer Institute. Recurrent Acute Myeloid Leukemia with Myelodysplasia-

Related Changes. NCI Thesaurus. Code C125715.

The reemergence of acute myeloid leukemia with myelodysplasia-related changes after a period of remission. 